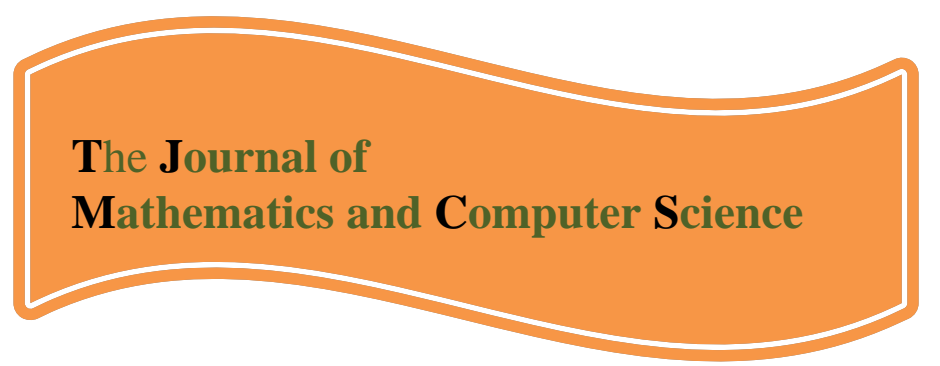

Available online at

\title{
http://www.TJMCS.com
}

The Journal of Mathematics and Computer Science Vol .2 No.1 (2011) 150-159

\section{Introducing a new method to expand TOPSIS decision making model to fuzzy TOPSIS}

\author{
Ali mohammadi' ${ }^{1}$ Abolfazl mohammadi ${ }^{2}$, hossain aryaeefar ${ }^{3}$ \\ 1-amohammadi_ie@yahoo.com \\ 2-a.mohammadi.che@gmail.com \\ 3-hossainaryaeefar@gmail.com
}

Received: August 2010, Revised: October 2010

Online Publication: January 2011

\begin{abstract}
Fuzzy TOPSIS is one of the various models of multiple attributes decision making with fuzzy values that so far diverse models have been introduced for it. In this paper, according to these models, a new method is presented for fuzzy TOPSIS with triangular fuzzy data. So, it has better and more accurate outputs in comparison with previous methods. At last, we solve a fuzzy multiple attributes decision making problem to demonstrate the proposed method.
\end{abstract}

Keywords: fuzzy TOPSIS, fuzzy number, linguistic variables, triangular fuzzy number.

\footnotetext{
${ }^{1, *}$ Isalamic Azad University-Bojnourd Branch.

${ }^{2}$, Chemical Engineering Phd Student, Engineering College of Tarbiat Modares University, Tehran,Iran.

3, Industrail Engineering BSc Student, Engineering Faculty of Bojnourd University.
} 


\section{Introduction}

TOPSIS method is one of the best grading methods of multi criteria decision making (MCDM) that is taken place in compromising -subgroup of compensating models of decision making. [1] As indicators are fuzzy in many decision making problems, scientists have tried to expand TOPSIS decision making model to fuzzy TOPSIS to solve such problems. (in the next part we are talking about some of these efforts),but in the models which have been introduced up to now , limits and problems have been seen that are due to characteristics of fuzzy numbers algebraic use such as multiple, division and so on.

In this paper in order to solve the problems of the presented models and by getting help from the definition (5).we present a new method to expand TOPSIS model to fuzzy TOPSIS that doesn't carry last problems and limits of last models and moreover, the proposed model is efficient in following three conditions:

A: When decision making matrix data is combination of fuzzy and crisp Values.

B: When decision making matrix data is just fuzzy value that can even consist of negative support

C: When decision making matrix data is just crisp number, so, the proposed model accurately is changed to TOPSIS model.

\section{Reviewing last models of fuzzy TOPSIS}

As it has been said in introduction many scientists made some efforts to expand TOPSIS model to fuzzy TOPSIS that some of them are following:

1- Chen,C.T., "Extensions of the TOPSIS for group decision-making under fuzzy environment", Fuzzy Sets and Systems 114,(2000), 1-9.

2- Deng, H., Yeh, C.H., Willis, R.J., "Inter-company comparison using modified TOPSIS with objective weights", Computers \& Operations Research, 2000, 27, pp. 963-973.

3- Chu,T.C., "Selecting plant location via a fuzzy TOPSIS approach", International Journal of Advanced Manufacturing Technology, accepted, 2001.

4- Chu, T.C., "Selecting plant location via a fuzzy TOPSIS approach", International Journal of Advance Manufacturing Technology, 2002: 859- 864.

5- Chu, T.C., "Facility location selection using fuzzy TOPSIS under group decisions", International Journal of Uncertainty, Fuzziness and Knowledge-Based Systems , 2002, 10(6), pp. 687-701.

6- Abo-Sina, M.A., Amer , A.H. "Extensions of TOPSIS for multi objective large-scale nonlinear programming problems", Applied Mathematics and Computation, 2004, Article in press

7- Abo-Sinha ,M.A., Amer ,A.H., "Extensions of TOPSIS for multi-objective large-scale nonlinear programming problems", Appl . Math. Comput . 162 (2005), 243-256.

8- Saghafian, S. and Hejazi, S. R., "Multi-Criteria Group Decision Making a Modified Fuzzy TOPSIS Procedure", Web Technologies and Internet Commerce, 2,215-221,(2005).

9- Jahanshaloo,G.R, Hosseinzadeh Lotfi,F., Izadikhah,M., "An algorithmic method to extend TOPSIS method for decisionmaking problems with interval data", Appl. Math. Comput. 175 (2006), 1375-1384.

10- Jahanshaloo,G.R, Hosseinzadeh Lotfi,F., Izadikhah,M., "Extension of the TOPSIS method for decision-making problems with fuzzy data", Appl. Math. Comput . 181 (2006), 1544-1551.

11- Hsu- Shih, Shih; Huan -Jyh, Shyur and E. Stanley, Lee , "An Extension of TOPSIS for Group Decision Making", An International Journal Mathematical and Computer Modeling, 45, 801-813, (2006) .

12- Wang,Y.J., Lee,H.S., "Generalizing TOPSIS for fuzzy multiple-criteria group decision-making", Comput. Math. Appl. 53,(2007), 1762-1772.

13- Chen,T.Y, Tsao,C.Y, "The interval-valued fuzzy TOPSIS method and experimental analysis" , Fuzzy Sets and Systems,159 (2008), 1410-1428.

14- Chu,T.-C., and Lin,Y.-C., "A Fuzzy TOPSIS Method for Robot Selection". 
15- Jin Han Park, Il Young Park ,Young Chel Kwun, Xuegong Tan, "Extension of the TOPSIS method for decision making problems under interval-valued intuitionist fuzzy environment".

16- Ertugrul, _I, \& Karakasoglu, N. ," Performance evaluation of Turkish cement firms with fuzzy analytic hierarchy process and TOPSIS methods" Expert Systems with Applications, 36(1), 702-715, (2007).

17- Wang, Y. M., \& Elhag, T. M. S."Fuzzy TOPSIS method based on alpha level sets with an application to bridge risk assessment",Expert Systems with Applications, 31, 309-319, (2006).

18- Wang ,J.W , Cheng, C.H., Cheng ,H. K" Fuzzy hierarchical TOPSIS for supplier selection" Applied Soft Computing, 9,pp. 377-386, (2009).

\section{TOPSIS DECISION MAKING METHOD}

The TOPSIS (technique for order performance by similarity to idea solution) was first developed by Hwang \& Yoon (1981). According to this technique, the best alternative would be the one that is nearest to the positive-ideal solution and farthest from the negative ideal solution (Ertugrul \& Karakasoglu, 2007). The positive- ideal solution is a solution that maximizes the benefit criteria and minimizes the cost criteria, whereas the negative ideal solution maximizes the cost criteria and minimizes the benefit criteria (Wang \& Elhag, 2006). In short, the positive-ideal solution is composed of all best values attainable from the criteria, whereas the negative ideal solution consists of all worst values attainable from the criteria (Wang, 2007). There have been lots of studies in the literature using TOPSIS for the solution of MCDM problems. (Chen, 2000; Chu \& Lin, 2002; Wang et al., 2009; Boran et al., 2009).

The calculation processes of the method are as following:

Step1. Establish a decision matrix for ranking. A MCDM problem can be concisely expressed in matrix format

As :

$\begin{array}{ccccccc} & c_{1} & c_{2} & \cdot & \cdot & \cdot & c_{n} \\ A_{1} & x_{11} & x_{12} & \cdot & \cdot & \cdot & x_{1 n} \\ A_{2} & x_{21} & x_{22} & \cdot & \cdot & . & x_{2 n} \\ \cdot & \cdot & \cdot & \cdot & \cdot & \cdot & \cdot \\ \cdot & \cdot & \cdot & \cdot & \cdot & \cdot & \cdot \\ . & \cdot & \cdot & \cdot & \cdot & \cdot & \cdot \\ A_{m} & x_{m 1} & x_{m 2} & \cdot & \cdot & \cdot & x_{m n}\end{array}$

where $A_{1}, A_{2}, \ldots, A_{m}$ are possible alternatives among which decision makers have to choose, $C_{1}, C_{2}, \ldots, C_{n}$ are criteria with which alternative performance are measured, $\mathrm{x}_{\mathrm{ij}}$ is the rating of alternative, $\mathrm{A}_{\mathrm{i}}$ with respect to criterion $\mathrm{C}_{\mathrm{j}}$.

Step 2. Calculate the normalized decision matrix. The normalized value $n_{\mathrm{ij}}$ is calculated as :

$$
n_{i j}=\frac{x_{i j}}{\sqrt{\sum_{i=1}^{m} x_{i j}^{2}}} \quad, j=1, \cdots, n
$$

Step 3. Calculate the weighted normalized decision matrix. The weighted normalized value $v_{i j}$ is calculated as :

$v_{i j}=w_{j} \times n_{i j} \quad, i=1, \ldots, \quad m, j=1, \ldots, \quad n$

Where $\mathrm{w}_{\mathrm{j}}$ is the weight if the ith criterion, and $\sum_{j=1}^{n} w_{j}=1$.

Step 4. Determine the positive ideal solutions and negative ideal solutions respectively : 


$$
\begin{aligned}
& A^{+}=\left\{\left(\left(\max _{i} v_{i j} \mid j \in J\right),\left(\min _{i} v_{i j} \mid j \in J^{\prime}\right)\right) \mid i=1,2, \ldots, m\right\}=\left\{v_{1}^{+}, v_{2}^{+}, \ldots, v_{m}^{+}\right\} \\
& A^{-}=\left\{\left(\left(\min _{i} v_{i j} \mid j \in J\right),\left(\max _{i} v_{i j} \mid j \in J^{\prime}\right)\right) \mid i=1,2, \ldots, m\right\},\left\{v_{1}^{-}, v_{2}^{-}, \ldots, v_{m}^{-}\right\}
\end{aligned}
$$

Where $J$ is associated with the positive criteria, and $J^{\prime}$ is associated with the negative criteria.

Step 5.Calculate the separation measures using the n-dimensional Euclidean distance. The separation of each alternative from the ideal solution is given as:

$d_{i}^{+}=\sqrt{\sum_{j=1}^{n}\left(v_{j}^{+}-v_{i j}\right)^{2}}, i=1,2, \ldots, m$

Similarly, the separation from the negative-ideal solution is given as

$d_{i}^{-}=\sqrt{\sum_{j=1}^{n}\left(v_{j}^{-}-v_{i j}\right)^{2}}, i=1,2, \ldots, m$

Step 6.Calculate the relative closeness to the ideal solution. The relative closeness of the alternative $A_{i}$ with respect to $A^{+}$is defined as:

$\mathrm{cl}_{i}^{+}=\frac{d_{i}^{+}}{d_{i}^{+}+d_{i}^{-}}, i=1,2, \ldots, \quad m$

Step 7.Rank the preference order. A large value of closeness coefficient $\mathrm{Cl}_{i}^{+}$indicates a good performance of the alternative Ai .The best alternative is the one with the greatest relative closeness to the ideal solution.

\section{Definitions}

Definition 1- triangular fuzzy set:

A triangular fuzzy set is defined as following:

$$
\mu_{\tilde{A}}(x)=\left\{\begin{array}{rll}
0 & \text { for } & x \leq a \\
\frac{x-a}{m-a} & \text { for } & a \leq x \leq m \\
\frac{b-x}{b-m} & \text { for } & m<x \leq b \\
0 & \text { for } & b \leq x
\end{array}\right.
$$

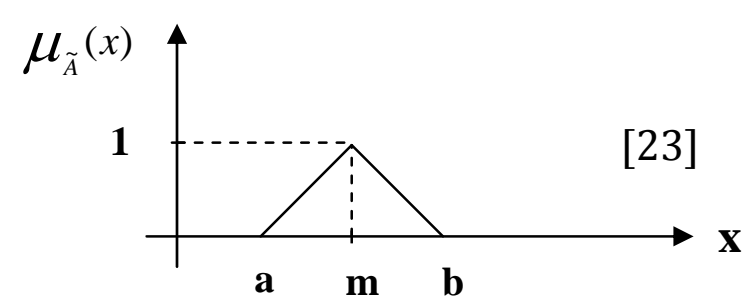

Definition 2- normal fuzzy set:

The fuzzy set which owns at least a member with the membership's rate of 1. [24]

Definition 3 - convex fuzzy set:

The fuzzy set $A$ is convex if: 


$$
\left\{\begin{array}{c}
\forall x_{1} \in X, \forall x_{2} \in X, \forall \lambda \in[0,1] \\
\mu_{\tilde{A}}\left(\lambda x_{1}+(1-\lambda) x_{2} \geq \min \left(\mu_{\tilde{A}}\left(x_{1}\right), \mu_{\tilde{A}}\left(x_{2}\right)\right)\right.
\end{array}\right.
$$

Definition 4- fuzzy number:

We call the set A as a fuzzy number if:

1 -it is normal

2 -it is convex

3- Its membership's function is continuous fragmentarily

4. The support and the scope are limit and definite. [24]

For example: we can define the approximate number 1.3 as a triangular fuzzy number as following

$$
\mu_{\tilde{A}}(x)=\left\{\begin{array}{c}
0 \text { for } x \leq 1.2 \\
10(x-1.2) \text { for } 1.2 \leq x \leq 1.3 \\
10(1.4-x) \text { for } 1.3\langle x \leq 1.4 \\
0 \text { for } 1.4 \leq x
\end{array}\right.
$$

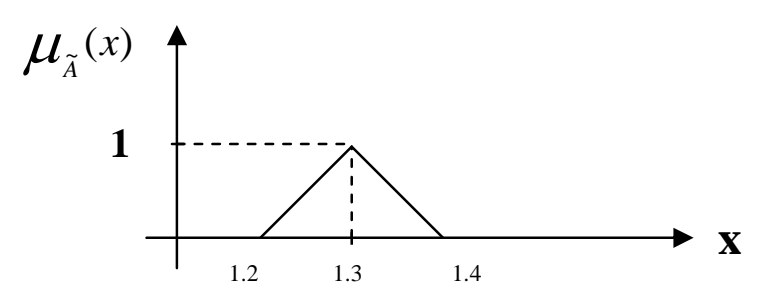

Attention: if A is a triangular fuzzy number with following membership's functions:

$\mu_{\tilde{A}}(x)=\left\{\begin{array}{rll}0 & \text { for } & x \leq a \\ \frac{x-a}{m-a} & \text { for } & a \leq x \leq m \\ \frac{b-x}{b-m} & \text { for } & m<x \leq b \\ 0 & \text { for } & b \leq x\end{array}\right.$

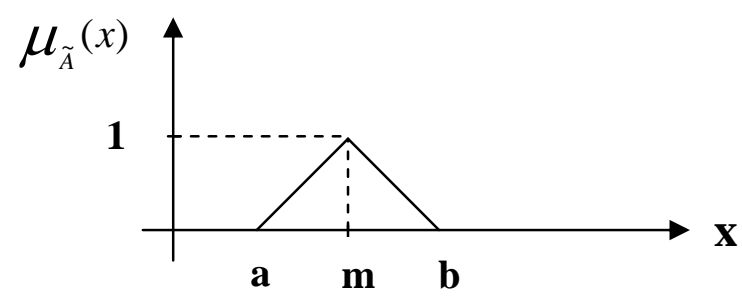

The number is shown in the front form: $\tilde{A}=(a, m, b)$

For instance the triangular fuzzy number 1.3 is shown below:

$$
\widetilde{A}=(1.2,1.3,1.4)
$$

Definition 5-The distance of two triangular fuzzy numbers:

If $\tilde{A}=\left(a_{1}, a_{2}, a_{3}\right), \widetilde{B}=\left(b_{1}, b_{2}, b_{3}\right)$ are two triangular fuzzy numbers, then the distance of $\tilde{A}$ from $\tilde{B}$ is achieved by following relation:

$$
S(\tilde{B}, \tilde{A})=\frac{\left(b_{1}+2 b_{2}+b_{3}\right)-\left(a_{1}+2 a_{2}+a_{3}\right)}{4}
$$

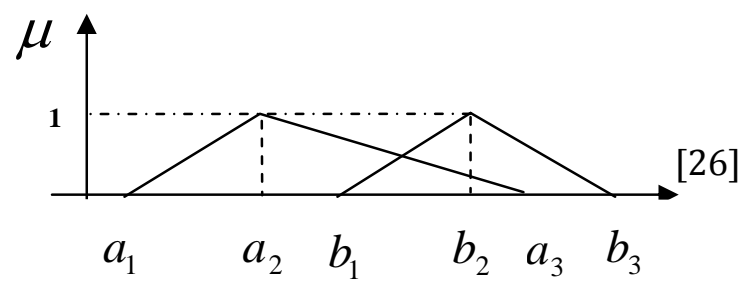


It is clear that the distance of the triangular fuzzy number $\tilde{A}$ the crisp number 0 equals following value:

$S(\tilde{A}, 0)=\frac{\left(a_{1}+2 a_{2}+a_{3}\right)}{4}$

\section{The proposed fuzzy TOPSIS method}

The steps of the proposed fuzzy TOPSIS method are following:

Step1. Establish a decision matrix for ranking. A MCDM problem can be concisely expressed in matrix format as:

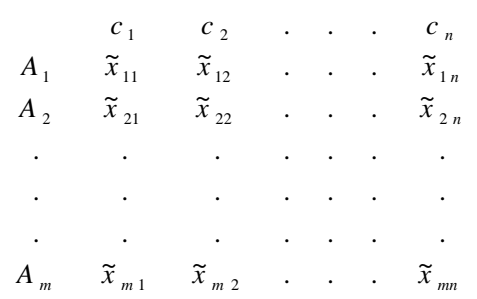

where $A_{1}, A_{2}, \ldots, A_{m}$ are possible alternatives among which decision makers have to choose, $C_{1}, C_{2}, \ldots, C_{n}$ are criteria with which alternative performance are measured, $\tilde{x}_{i j}=\left(x_{i j}^{a}, x_{i j}^{b}, x_{i j}^{c}\right)$ is the fuzzy rating of alternative, $\mathrm{A}_{\mathrm{i}}$ with respect to criterion $\mathrm{C}_{\mathrm{j}}$.

Step 2.Calculate the normalized decision matrix. The normalized value $\tilde{n}_{i j}=\left(n_{i j}^{a}, n_{i j}^{b}, n_{i j}^{c}\right)$ is calculated as :

$\tilde{n}_{i j}=\frac{\tilde{x}_{i j}}{\sqrt{\sum_{i=1}^{m}\left(s\left(\tilde{x}_{i j}, 0\right)\right)^{2}}}, j=1, \cdots, n$

Where $s\left(\tilde{x}_{i j}, 0\right)=\frac{x_{i j}^{a}+2 x_{i j}^{b}+x_{i j}^{2}}{4}$

Step 3.Calculate the weighted normalized decision matrix. The weighted normalized value $\tilde{v}_{i j}=\left(v_{i j}^{a}, v_{i j}^{b}, v_{i j}^{c}\right)$ is calculated as:

1- If $\mathrm{w}$ is a crisp value:

$\tilde{v}_{i j}=w_{j} \times \tilde{n}_{i j} \quad, i=1, \ldots, m, j=1, \ldots, n$

Where $\mathrm{w}_{\mathrm{j}}$ is the weight if the ith criterion, and $\sum_{j=1}^{n} w_{j}=1$.

2-if $\mathrm{w}$ is a triangular fuzzy value:

$\tilde{v}_{i j}=\left(s\left(\tilde{w}_{j}, 0\right)\right) \times \tilde{n}_{i j}=\left(\left(s\left(\widetilde{w}_{j}, 0\right)\right) \times n_{i j}^{a},\left(s\left(\tilde{w}_{j}, 0\right)\right) \times n_{i j}^{b},\left(s\left(\widetilde{w}_{j}, 0\right)\right) \times n_{i j}^{c}\right), i=1,2, \ldots, m, j=1,2, \ldots, n$

Where $\mathrm{w}_{\mathrm{j}}$ is the weight if the $i$ th criterion, and $\sum_{j=1}^{n} s\left(\tilde{w}_{j}, 0\right)=1 ; s\left(\widetilde{w}_{j}, 0\right) \geq 0, j=1,2, \ldots, n$.

Step 4.Determine the positive ideal solutions and negative ideal solutions respectively: 


$$
\begin{aligned}
& A^{+}=\left\{\tilde{v}_{1}^{+}, \tilde{v}_{2}^{+}, \ldots, \tilde{v}_{n}^{+}\right\}=\left\{\left(\tilde{v}_{u j} \mid j \in J\right),\left(\tilde{v}_{d j} \mid j \in J^{\prime}\right)\right\} \\
& A^{-}=\left\{\tilde{v}_{1}^{-}, \tilde{v}_{2}^{-}, \ldots, \tilde{v}_{n}^{-}\right\}=\left\{\left(\tilde{v}_{d j} \mid j \in J\right),\left(\tilde{v}_{u j} \mid j \in J^{\prime}\right)\right\}
\end{aligned}
$$

Where:

$J$ is associated with the positive criteria

$J$ ' is associated with the negative criteria

$\mathrm{U}$ is the value between 1 to $\mathrm{m}$ that $\tilde{v}_{u j}$ has the most distance from the crisp number 0 ,it means:

$$
s\left(\tilde{v}_{u j}, 0\right) \geq s\left(\tilde{v}_{i j}, 0\right) \quad, i=1,2, \ldots, m
$$

$\mathrm{D}$ is the value between 1 to $\mathrm{m}$ that $\tilde{v}_{d j}$ has the most distance from the crisp number 0 ,it means

$$
s\left(\tilde{v}_{d j}, 0\right) \leq s\left(\tilde{v}_{i j}, 0\right) \quad, i=1,2, \ldots, m
$$

Step 5.Calculate the separation measures using the n-dimensional Euclidean distance. The separation of each alternative from the positive-ideal solution is given as:

$d_{i}^{+}=\sqrt{\sum_{j=1}^{n}\left(s\left(\tilde{v}_{j}^{+}, \tilde{v}_{i j}\right)\right)^{2}}, i=1,2, \ldots, m$

Similarly, the separation from the negative-ideal solution is given as

$d_{i}^{-}=\sqrt{\sum_{j=1}^{n}\left(s\left(\tilde{v}_{j}^{-}, \tilde{v}_{i j}\right)\right)^{2}}, i=1,2, \ldots, m$

Step 6.Calculate the relative closeness to the ideal solution. The relative closeness of the alternative $A_{i}$ with respect to $A^{+}$is defined as:

$$
c l_{i}^{+}=\frac{d_{i}^{+}}{d_{i}^{+}+d_{i}^{-}}, i=1,2, \ldots, \quad m
$$

Step 7.Rank the preference order. A large value of closeness coefficient $\mathrm{Cl}_{i}^{+}$indicates a good performance of the alternative $A_{i}$.The best alternative is the one with the greatest relative closeness to the ideal solution.

\section{Example}

suppose that we grade three alternatives $A, B, C$ according to the indicators $\mathrm{I}_{1}, \mathrm{I}_{2}, \mathrm{I}_{3}$ that their weights are respectively $0.25,0.5$ and 0.25 and grade by the proposed fuzzy TOPSIS method, the indicators $\mathrm{I}_{1}$ and $\mathrm{I}_{3}$ are from income type and $\mathrm{I}_{2}$ from cost type, so, we do like following:

First step: Establish decision making Matrix: suppose that it is like below according to the information:

\begin{tabular}{|c|c|c|c|}
\hline indicator & $\mathbf{I}_{\mathbf{1}}$ & $\mathbf{I}_{\mathbf{2}}$ & $\mathbf{I}_{\mathbf{3}}$ \\
\hline alternative & & & \\
\hline $\mathbf{A}$ & $(-1,2,3)$ & $(5,8,9)$ & $(20,2,3)$ \\
\hline $\mathbf{B}$ & $(0,2,4)$ & $(4,6,9)$ & $(15,17,20)$ \\
\hline $\mathbf{C}$ & $(0,1,2)$ & $(1,3,7)$ & $(17,22,25)$ \\
\hline
\end{tabular}


Second step: making normalized matrix: we use following relation to get normalized matrix

$$
\begin{aligned}
& \tilde{n}_{i j}=\frac{\tilde{x}_{i j}}{\sqrt{\sum_{i=1}^{m}\left(s\left(\tilde{x}_{i j}, 0\right)\right)^{2}}} \quad, j=1, \cdots, n \\
& n_{11}=\frac{(-1,2,3)}{\sqrt{\left(\frac{-1+4+3}{4}\right)^{2}+\left(\frac{0+4+4}{4}\right)^{2}+\left(\frac{0+2+2}{4}\right)^{2}}}=\frac{(-1,2,3)}{2.69}=(-0.37,0.74,1.12)
\end{aligned}
$$

Other methods of normalized matrix are computed in the same relation and so:

\begin{tabular}{|c|c|c|c|}
\hline Indicator & $\mathbf{I}_{\mathbf{1}}$ & $\mathbf{I}_{\mathbf{2}}$ & $\mathbf{I}_{\mathbf{3}}$ \\
\hline alternative & $(0.37,0.74,1.12)$ & $(0.77,0.48,0.87)$ & $\begin{array}{c}, 0.71,0.68) \\
(0.55\end{array}$ \\
\hline $\mathbf{A}$ & & & $0.41, .47,0.55)$ \\
\hline $\mathbf{B}$ & $(0,0.74,1.48)$ & $(0.39,0.58,0.87)$ & $0.47,0.6,0.68)$ \\
\hline $\mathbf{C}$ & $(0,0.37,0.74)$ & $(0.1,0.29,0.68)$ & $(0.47$, \\
\hline
\end{tabular}

Third step: making weighted matrix:

At this stage we can make weighted matrix according to the following relation:

$$
\begin{aligned}
& \tilde{v}_{i j}=w_{j} \times \tilde{n}_{i j} \quad, i=1, \ldots, m, j=1, \ldots, n \\
& \tilde{v}_{12}=w_{2} \times \tilde{n}_{12}=0.5 \times(0.48,0.77,0.87)=(0.24,0.39,0.44)
\end{aligned}
$$

Others are computed in the same relation and so:

\begin{tabular}{|c|c|c|c|}
\hline indicator & $\mathbf{I}_{\mathbf{1}}$ & $\mathbf{I}_{\mathbf{2}}$ & $\mathbf{I}_{3}$ \\
\hline alternative & $(-$ & $(0.24,0.39,0.44)$ & $(0.14,0.17,0.18)$ \\
\hline $\mathbf{A}$ & $0.09,0.19,0.28)$ & & \\
\hline $\mathbf{B}$ & $(0,0.19,0.38)$ & $(0.2,0.29,0.44)$ & $(0.1,0.12,0.14)$ \\
\hline C & $(0,0.09,0.19)$ & $(0.05,0.15,0.34)$ & $(0.12,0.15,0.17)$ \\
\hline
\end{tabular}

Fourth step: comparing negative and positive ideal solution:

As an example if we want to compute the positive ideal value of the indicator $\mathrm{I}_{1}$, we do as following: First in the indicator $\mathrm{I}_{1}$, we compute the distance of the values $\mathrm{A}, \mathrm{B}$ and $\mathrm{C}$ from 0 .

$s((-0.09,0.19,0.28), 0)=\frac{-0.09+0.38+0.28}{4}=0.142$

$s((0,0.19,0.38), 0)=\frac{0+0.38+0.38}{4}=0.19$

$s((0,0.09,0.19), 0)=\frac{0+0.18+0.38}{4}=0.14$

Because in the indicator $I_{1}$, (that $I_{1}$ is positive's criteria)the distance of the alternative $B$ from 0 is more than the alternatives $A$ and $C$, the value of this alternative is chosen as ideal positive value in this indicator according to the indicator $I_{1}$.it means $\widetilde{v}_{1}^{+}=(0,0.19,0.38)$

And like the same relation : 


$$
\begin{aligned}
& A^{+}=\left\{\tilde{v}_{1}^{+}, \tilde{v}_{2}^{+}, \ldots, \tilde{v}_{n}^{+}\right\}=\{(0,0.19,0.38),(0.5,0.15,0.34),(0.14,0.17,0.18)\} \\
& A^{-}=\left\{\tilde{v}_{1}^{-}, \tilde{v}_{2}^{-}, \ldots, \tilde{v}_{n}^{-}\right\}=\{(0,0.09,0.19),(0.24,0.39,0.44),(0.1,0.12,0.14)\}
\end{aligned}
$$

Fifth step: computing the distance of each alternative from positive and negative ideal:

We do the following relations to compute them:

$$
\begin{aligned}
& d_{i}^{-}=\sqrt{\sum_{j=1}^{n}\left(s\left(\tilde{v}_{j}^{-}, \tilde{v}_{i j}\right)\right)^{2}}, i=1,2, \ldots, m \\
& d_{i}^{+}=\sqrt{\sum_{j=1}^{n}\left(s\left(\tilde{v}_{j}^{+}, \tilde{v}_{i j}\right)\right)^{2}}, i=1,2, \ldots, m
\end{aligned}
$$

As an example:

$d_{1}^{+}=\sqrt{\sum_{j=1}^{n}\left(\frac{0+0.38+0.38+0.09-0.38-0.28}{4}\right)^{2}+\left(\frac{0.24+0.78+0.44+0.05+0.3+0.34}{4}\right)^{2}+\left(\frac{0.14+0.34+0.18+0.14-0.34-0.18}{4}\right)^{2}}=0.21$

Others are computed in the same way

$d_{2}^{+}=0.15, d_{3}^{+}=0.1, d_{1}^{-}=0.08, d_{2}^{-}=0.12, \quad d_{3}^{-}=0.2$

Sixth step: computing the relative distance of each alternative from positive ideal:

We compute them by following relation:

$$
\begin{aligned}
& \mathrm{cl}_{i}^{+}=\frac{d_{i}^{+}}{d_{i}^{+}+d_{i}^{-}}, i=1,2, \ldots, \quad \mathrm{m} \\
& \mathrm{cl}_{1}^{+}=\frac{0.21}{0.21+0.08}=0.73 \\
& \mathrm{cl}_{2}^{+}=0.56 \quad, \quad \mathrm{cl}_{3}^{+}=0.33
\end{aligned}
$$

Seventh step: grading alternatives:

At this step we arrange the values respectively that are computed in the last step, so, the number with the lowest value of relative distance shows the first preference.

So, in this example, the alternative $\mathrm{C}$ is in the first preference, the alternative $\mathrm{B}$ second preference and $\mathrm{A}$ is the third preference.

\section{Conclusion:}

In this paper a new method has been presented to expand TOPSIS decision making model to fuzzy TOPSIS with triangular fuzzy data by considering computation mode of the distance between two fuzzy numbers which are brought in the definition [5].

Regarding the steps of the proposed model deeply and its results due to solve presented examples, clearly show efficiency and rationality of the proposed method.

From other considerable points in this proposed model we can say following issues:

1. Its simplicity and comprehensible mode for all

2. Big similarity of the proposed model to TOPSIS model

3. Solving the problems and limits of fuzzy TOPSIS last methods

4.its usage capability to solve decision making problems whose decision making matrix data consist of just crisp , just fuzzy, combination of fuzzy and crisp data.

5. Equal outputs of the proposed method with TOPSIS method when decision making data is crisp number in both models.

6. Expansion capability of the proposed model to other fuzzy numbers (such as trapezoidal, s-curve, etc) 


\section{References:}

1- asgharpour , m.j., "multi-indicator decision making";Tehran university publishment ,first edition,1999.

2- Chen,C.T., "Extensions of the TOPSIS for group decision-making under fuzzy environment", Fuzzy Sets and Systems 114,(2000), 1-9.

3- Deng, H., Yeh, C.H., Willis, R.J., "Inter-company comparison using modified TOPSIS with objective weights", Computers \& Operations Research, 2000, 27, pp. 963-973.

4- Chu,T.C., "Selecting plant location via a fuzzy TOPSIS approach", International Journal of Advanced Manufacturing Technology, accepted, 2001.

5- Chu, T.C., "Selecting plant location via a fuzzy TOPSIS approach", International Journal of Advance Manufacturing Technology, 2002: 859- 864.

6- Chu, T.C., "Facility location selection using fuzzy TOPSIS under group decisions", International Journal of Uncertainty, Fuzziness and Knowledge-Based Systems , 2002, 10(6), pp. 687-701.

7- Abo-Sina, M.A., Amer , A.H. "Extensions of TOPSIS for multi objective large-scale nonlinear programming problems", Applied Mathematics and Computation, 2004, Article in press

8- Abo-Sinha ,M.A., Amer ,A.H., "Extensions of TOPSIS for multi-objective large-scale nonlinear programming problems", Appl . Math. Comput . 162 (2005), 243-256.

9- Saghafian, S. and Hejazi, S. R., "Multi-Criteria Group Decision Making a Modified Fuzzy TOPSIS Procedure", Web Technologies and Internet Commerce, 2,215-221,(2005).

10- Jahanshaloo,G.R, Hosseinzadeh Lotfi,F., Izadikhah,M., "An algorithmic method to extend TOPSIS method for decisionmaking problems with interval data", Appl. Math. Comput. 175 (2006), 1375-1384.

11- Jahanshaloo,G.R, Hosseinzadeh Lotfi,F., Izadikhah,M., "Extension of the TOPSIS method for decision-making problems with fuzzy data", Appl. Math. Comput. 181 (2006), 1544-1551.

12- Hsu- Shih, Shih; Huan -Jyh, Shyur and E. Stanley, Lee (2006), "An Extension of TOPSIS for Group Decision Making", An International Journal Mathematical and Computer Modeling, 45, 801-813 .

13- Wang,Y.J., Lee,H.S., "Generalizing TOPSIS for fuzzy multiple-criteria group decision-making", Comput. Math. Appl. 53,(2007), 1762-1772.

14- Chen,T.Y, Tsao,C.Y, "The interval-valued fuzzy TOPSIS method and experimental analysis" , Fuzzy Sets and Systems,159 (2008), 1410-1428.

15- Chu,T.-C., and Lin,Y.-C., "A Fuzzy TOPSIS Method for Robot Selection".

16- Jin Han Park, Il Young Park ,Young Chel Kwun, Xuegong Tan, "Extension of the TOPSIS method for decision making problems under interval-valued intuitionist fuzzy environment".

17- Ahmadi,G.A.A., Taghipourian,M.J., and Taghipourian,Y.,"The evaluation of instructors TRAINING Performance by fuzzy MCDM", Proceedings of the $2^{\text {nd }}$ International Conference of Teaching and Learning (ICTL 2009) INTI University College, Malaysia

18- Ertugrul, _I, \& Karakasoglu, N. ," Performance evaluation of Turkish cement firms with fuzzy analytic hierarchy process and TOPSIS methods" Expert Systems with Applications, 36(1), 702-715, (2007).

19- Wang, Y. M., \& Elhag, T. M. S."Fuzzy TOPSIS method based on alpha level sets with an application to bridge risk assessment",Expert Systems with Applications, 31, 309-319, (2006).

20- Wang, Y. J. ," Applying FMCDM to evaluate financial performance of domestic airlines in Taiwan",Expert Systems with Applications. 10.1016/j.eswa.2007. 02.029, (2007).

21- Wang ,JW , Cheng, C.H., Cheng ,H. K" Fuzzy hierarchical TOPSIS for supplier selection" Applied Soft Computing, 9,pp. 377-386, (2009).

22- Boran, F. \& Gen, S. \& Kurt, M. \& Akay D., " A multi-criteria intuitionist fuzzy group decision making for supplier selection with TOPSIS method", Expert Systems with Applications, doi:10.1016/j.eswa.2009.03.039, (2009).

23- color,J.J.,color,U.S.,Uann,B.,"fuzzy sets theory,principles and yields".

24- NURANI,.M., "fuzzy numbers and their comparing methods", the AM thesis , kerman university,1999.

24- Zimmermann,H.J., "Fuzzy Set Theory and its Applications" ,2nd edn. Kluwer Academic Publishers, Boston/Dordrecht/London, 1991.

25- mohammadi,a., shohani,j.,jahanshahi,h.,"numerical taxonomy analysis with triangular fuzzy data",the $10^{\text {th }}$ conference of fuzzy systems,iran,shahid beheshti university,2010. 